\title{
EPISTEMOFAGIA TRANSFORMADORA: SABERES LOCAIS E INCLUSÃO NO ENSINO SUPERIOR BRASILEIRO
}

Clarissa Menezes Jordão*

RESUMO: Este texto apresenta o conceito de "epistemofagia" em referência ao movimento cultural brasileiro modernista dos anos 1920. Em seguida, descreve um programa universitário analisado como "epistemofágico", já que desenvolvido com o propósito explícito de (1) desafiar pressupostos sobre a natureza do conhecimento acadêmico, como ele é construído, valorizado e distribuído, bem como de (2) apresentar alternativas às posições de sujeito ocupadas por professores e alunos universitários. $\mathrm{Na}$ tentativa de incluir conhecimentos locais na cena acadêmica, esse programa universitário, portanto, é concebido, aqui, como demandando, por um lado, uma epistemologia do conhecer como uma atividade colaborativa e contextualmente construída, e, por outro, possibilitando uma ontologia informada por identidades locais e globais em sua relação com o conhecimento institucionalizado.

Palavras-chave: Conhecimento; Educação Superior; Currículo.

\section{TRANSFORMATIVE EPISTEMOPHAGY:} LOCAL KNOWLEDGES AND INCLUSION IN BRAZILIAN HIGHER EDUCATION

ABSTRACT: This text starts from contextualizing higher education in Brazil in terms of identity and culture, and presenting the idea of "epistemophagy" in reference to a modernist Brazilian cultural movement of the 1920's. It then moves on to a description and analysis of a specific "epistemophagic" university program designed to challenge assumptions of what constitutes academic knowledge, how it is formed, valued and distributed, as well as to develop alternatives to subject positions occupied by university professors and students. In an attempt to include local knowledge in the academic scene, this higher education program therefore is conceived as claiming, on the one hand, for an epistemology that views knowledge as collaboratively and contextually built and, on the other hand, an ontology that seeks to reexamine local and global identities in their relation to institutionalized knowledge.

Keywords: Knowledge; Higher Education; Curriculum.

*Doutora em Letras pela Universidade de São Paulo (USP); Professora da Universidade Federal do Paraná (UFPR). E-mail: clarissamjordao@gmail.com

Educação em Revista | Belo Horizonte | v.27 | n.02 | p.249-276 | ago. 2011 
Nosso país tem se preocupado com sua relação com o mundo desde que passamos a ter registros históricos, embora durante muito tempo tal preocupação possa ter sido caracterizada como algo diferente de globalização - invasão numa época, interferência em outra, influência em outra ainda. Em 1928, por exemplo, a cultura brasileira "culta" foi sacudida por um movimento artístico interno conhecido como Modernismo, dentro do qual se costuma posicionar o Manifesto Antropofágico de Oswald de Andrade (TELES, 1976).

Esse manifesto foi escrito numa combinação de várias línguas (desde línguas nativas locais até português, francês e inglês) e anunciava a antropofagia como uma característica nacional: a justificativa era de que nós brasileiros tenderíamos a assimilar o estrangeiro, digeri-lo e assim separar o joio do trigo, armazenando o bom e expulsando o que não é bom, mas sempre transformando, no processo, aquilo que é digerido, assim como quem digere. Tal metáfora, ancorada no processo digestivo, tem sido constantemente usada em referência ao chamado "cadinho cultural" brasileiro e a nosso comportamento em relação a outras culturas, representado como receptivo e assimilador da cultura alheia, caracterizando o país como um melting pot. A frase mais citada do Manifesto, "tupi or not tupi, that is the question", faz alusão explícita ao que se costuma enfatizar como característica marcante de nossa identidade nacional: a calorosa abertura à diferença, sua aceitação e recontextualização.

O Manifesto, ao mesmo tempo que critica a história patriarcal e colonial imitativa, com seus valores importados e acriticamente emprestados da Europa, também defende utopicamente a realização de uma história futura matriarcal baseada nas sociedades autóctones do Brasil indígena pré-colonial. Nesse Manifesto, o contrato entre o local e o global, o nacional e o estrangeiro é trazido à tona e desafiado em suas implicações culturais e econômicas; o Manifesto constrói um jogo de sombra e luz ambivalente, num tom positivo e ufanista, nas relações interculturais, temporais e espaciais entre o Brasil e outros países, culturas e economias.

Essa natureza supostamente miscigenada e receptiva da cultura brasileira, presente na representação que o Brasil constrói de si mesmo, 
elaborada tanto por um olhar interno quanto também pelo olhar do outro, parece no entanto ter ficado restrita à cultura popular cotidiana e talvez ao campo das artes. Quando se trata de conhecimento científico, nossa história se conta em tons diferentes. Nessa formação discursiva, a narrativa de nós mesmos tende a dizer que somos um país de intelectuais que não produzem teoria, mas simplesmente a importam do Norte Global; nossa narrativa diz que as universidades brasileiras não conseguem manter os raros intelectuais que parecemos produzir: os poucos sobreviventes ocasionalmente encontrados são atraídos pela infraestrutura da academia no exterior, contribuindo largamente para o fenômeno global do "brain drain".

Certamente não nos orgulhamos desse traço cultural, econômico, político. Mas orgulhamo-nos em afirmar que nosso sistema educacional, especialmente no ensino superior, segue o modelo europeu (francês ou napoleônico em sua vertente profissionalizante e com as faculdades; alemão humboldtiano com o desejo pela ciência desinteressada que nos parece ter chegado via Estados Unidos, na reforma brasileira de 1968, conforme apontam Pimenta e Anastasiou, 2002), segue os moldes criados no "centro da civilização" e no "âmago do mundo científico". A necessidade de adaptar um sistema educacional importado traz consigo a necessidade progressiva de controle, a fim de serem mantidas as características "essenciais" do modelo, que supostamente garantirão a qualidade das instituições de ensino superior e os serviços prestados à sociedade.

Essa responsabilidade pelo controle e pela consequente garantia de qualidade caberia ao governo federal, por meio do MEC e da CAPES, regulamentando os cursos de graduação de acordo com critérios balizados pelos modelos construídos a partir da referência estrangeira. Tal controle surge e se acirra, cada vez mais, em termos de recompensas aos que mais produzem quantitativamente, ou seja, a produção é tida como sinônimo de número de publicações - as tentativas de qualificar publicações, tanto de periódicos quanto de livros, são constantemente alvo de protestos e se mostram sempre falhas, já que representam tentativas de congelar o movimento constante do saber na categorização do que seria nacionalmente (ou universalmente) melhor ou pior.

É nesse pano de fundo que têm surgido algumas tentativas de questionar as alegações tradicionais que colocam a ciência como sendo 
uma atividade humana objetiva, neutra e abstrata. Tais alegações desconectam a ciência da vida cotidiana e de elementos de engajamento pessoal, promovendo a descorporificação (FOUCAULT, 2002) da ciência e assim mantendo-a afastada das preocupações e atividades diárias das pessoas. Paulo Freire promoveu a ideia de que ler o mundo não é simplesmente oferecer uma descrição de sua natureza, das coisas como "realmente são"; mais do que isso, ao nomear e ler o mundo estamos construindo esse mundo - ler/nomear a realidade é escrever o mundo, e fazer isso de modo crítico é modificá-lo.

O trabalho de Freire foi uma tentativa de reposicionar o conhecimento na sociedade. O Manifesto Antropofágico foi outra. Os efeitos dessas tentativas de reposicionamento do conhecimento e de formas de conhecer reverberam também na cultura universitária e, neste texto, trato de apresentar, em maiores detalhes, uma dessas tentativas, desta vez dentro do espaço de um curso de graduação em Letras, cujos planejamento e implementação têm sido experienciados em situação de imersão no ambiente profissional cotidiano em que acontece a formação continuada "informal" de professores universitários.

\section{0 currículo}

O programa de graduação em Letras na Universidade Federal do Paraná conta com sete línguas estrangeiras, sendo que existe um currículo diferenciado para duas delas, japonês e polonês. Os programas de línguas estrangeiras do curso para Francês, Inglês, Espanhol, Alemão e Italiano seguem os moldes tradicionais de currículo disciplinar conteudista, baseados numa estrutura transmissiva que Freire chamou de "educação bancária", um processo no qual os professores são os depositantes de conhecimento nas de outro modo vazias contas bancárias dos alunos. O currículo diferenciado mais recente foi criado no Departamento de Letras Estrangeiras Modernas para as habilitações em Japonês e Polonês, e teve início em 2009, com a entrada de dez alunos para o polonês e 20 para o japonês.

Antes de descrever em maiores detalhes as inovações desse formato curricular dos novos cursos, é preciso apresentar alguns pressupostos teóricos que informaram a construção desse currículo, a fim de faci- 
litar a compreensão de suas características. $O$ processo de apresentação dessa concepção curricular funciona também como espaço para situar a perspectiva epistemológica dos professores participantes do currículo e responsáveis por seu processo de construção e atual implementação.

A primeira e talvez principal pressuposição que orienta o currículo é que a cognição é uma atividade fundada em relações de contato e interação, num movimento que ocorre simultaneamente para dentro e para fora, num processo que coloca em jogo elementos sociais e individuais ao mesmo tempo (FARACO, 2005). Tal entendimento de cognição implica que o que outros dizem sobre nós, bem como os modos pelos quais interpretamos o que dizem e o que pensamos sobre nós mesmos e sobre os outros ou, em outras palavras, os modos como nos relacionamos com o mundo, estão intimamente entrelaçados (ver Figura 1), afetando os modos como nossas identidades são construídas, estabelecidas e restabelecidas. Consequentemente, identidade é também um processo formado em uma miríade de relações, num "multiverso" (MATURANA, 1992) onde constantemente criamos e recriamos diferentes formas de interação entre vários elementos diferentes.

\section{Figura 1 - Cognição}

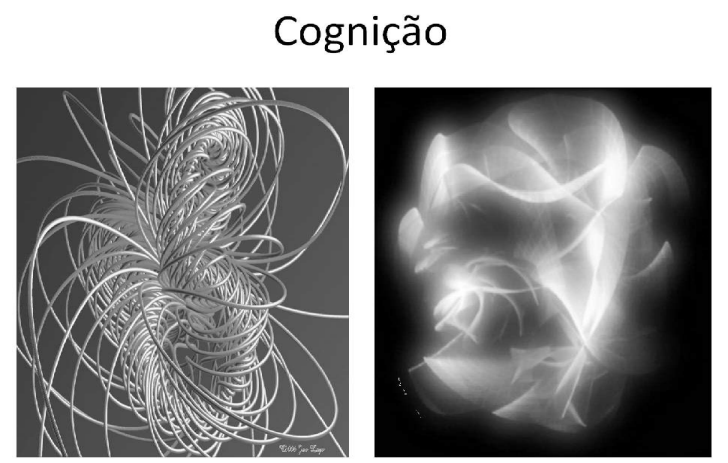

Fonte: http://knoll.google.com/k/hamid-javanbakht/polytelesis

O teórico cultural jamaicano Stuart Hall prefere inclusive a palavra "identificação" a "identidade", já que a primeira lhe parece enfatizar o caráter dinâmico e heterogêneo do processo. Para Hall (2005), a palavra "identificação" reflete melhor o movimento de articulação envolvido no 
processo de construção de identidades, um processo visto por ele como uma atividade de costura que às vezes cose remendos específicos que podem, em algum momento, ficar mais soltos ou mais apertados, desfazerse ou mesmo organizar-se de outros modos conforme o tempo, lugar e circunstâncias de sua existência. $\mathrm{Na}$ identificação, continua Hall, há sempre “'demasiado' ou 'muito pouco' - um excesso ou uma falta, mas nunca um ajuste perfeito ou uma totalidade [...] ela envolve um processo discursivo, o fechamento e a marcação de fronteiras simbólicas, a produção de 'efeitos de fronteira"' (HALL, 2005, p. 16). Nossas identidades, portanto, são identificações contingentes, provisoriamente construídas num processo simbólico de seleção contextual e relação (estabelecido em circunstâncias concretas de tempo e espaço) entre elementos culturais conectados em padrões, que se formam conforme interpretamos e somos interpretados pelos espaços discursivos que habitamos. Na mesma linha de pensamento, o espanhol Manuel Castells também pensa na pluralidade e instabilidade de nossas identificações como causas de estresse e conflito, pois forçam os sujeitos a se entenderem em constante "contradição tanto no processo de representação individual quanto no de ação social" (2003, p. 6).

Essa visão sobre o processo de identificação permite explorar o segundo pressuposto importante na discussão sobre o currículo tematizado aqui: a concepção de linguagem não como um produto, mas como uma atividade que constitui nossas identidades e realidades, um elemento que faz coisas em vez de meramente mediar elementos externos a si mesmo (ver Figura 2).

Consequentemente, a linguagem não é um elemento conectando pensamento e matéria, ou fazendo a ponte entre o sujeito e sua realidade: linguagem é realidade, no sentido em que é na linguagem que construímos nossos sentidos e entendimentos de mundo. Isso não significa dizer que a realidade não existe; em vez disso, significa negar a existência de objetos descorporificados, concebidos como "dados", como sendo independentes dos sujeitos que os interpretam e, ao interpretá-los, fazem-nos existir (JORDÃO, 2010).

A realidade é portanto, em nosso terceiro pressuposto, vista como discursiva e assim sempre heterogênea (FARACO, 2009), instável e repleta de contradições, geradora de tensões que tornam impossível seu fechamento e, desse modo, estabelecem uma necessidade constante de abertura e negociação como elementos de sobrevivência. 
FIGURA 2 - Linguagem como prática social: discurso

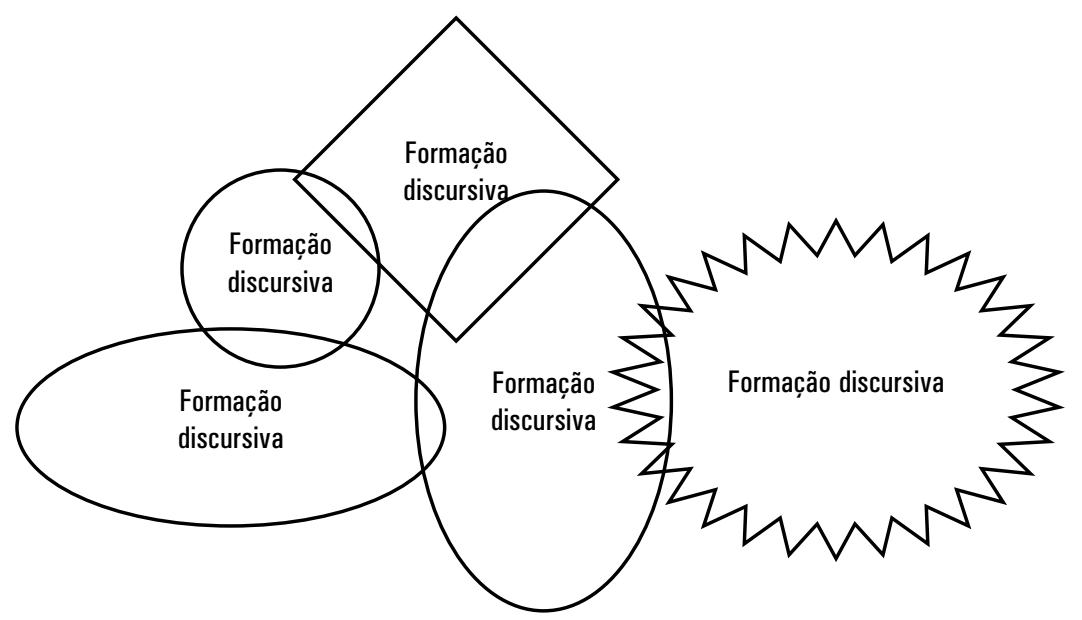

A ideia da instabilidade levando à abertura do sujeito precisa ser melhor explicada aqui. Comecemos por usar a palavra discurso para nos referirmos à linguagem, a fim de evitar a dicotomia usual entre estrutura - relacionada à linguagem - e agência - relacionada à atividade. Pensemos em linguagem como sendo tanto abstração quanto prática social na palavra discurso. Discursos são plurais e dinâmicos e, portanto, existem em relações de conflito nas quais diferentes elementos constantemente desafiam uns aos outros e se reposicionam temporariamente. É como se as formas da Figura 2 se movimentassem, mudando de lugar na imagem e passando de formas ovoides para esféricas, para retangulares, para ameboides, etc., ou mesmo se extinguissem e outras surgissem incessantemente. Discursos estão sempre em transformação num movimento complexo e dinâmico, o que confere a cada sujeito a oportunidade constante de imprimir seu próprio design ao movimento. Entretanto, como indivíduos sociais, nossas identidades desenvolvem-se num processo simultaneamente social e individual, um processo no qual os binários dentro/fora, estrutura/atividade (CHOMSKY, 2000), social/individual precisam ser vistos como simultâneos e complementares em vez de excludentes - precisamos conceber nossa relação com o mundo como uma relação complexa na qual muitos elementos e camadas estão em jogo, ao mesmo tempo, em cada contexto específico, todos lutando por reconhecimento. Essa noção estabelece a necessidade de reconhecer que a "realidade" depende de nos- 
sas posições no processo, das maneiras pelas quais interpretamos o processo, pelas quais cada um de nós vê o mundo e o constrói. Em outras palavras, nossas realidades e, portanto, nossos princípios e julgamentos ético-morais dependem de como vemos as coisas a partir das posições que ocupamos no processo.

Daí decorre um tipo de relativismo que frequentemente tem sido interpretado equivocadamente como uma inabilidade de posicionar-se, como uma atitude que levaria à aceitação de toda e qualquer coisa, já que todos teriam o direito de pensar e agir como quisessem. Mas na perspectiva relativista defendida aqui, que pode ser chamada de relativismo pós-estruturalista, não há relação de causa e efeito entre a inexistência de referenciais metafísicos normativos universais, por um lado, e a possibilidade de julgamento e arbitragem, por outro lado (TADDEI, 2000, p. 134).

Nosso quarto pressuposto se baseia nessa perspectiva para conceber diferentes entendimentos do mundo como sempre subjetivos e ideológicos, uma vez que não há como olhar para o mundo a partir de uma perspectiva descorporificada: os modos como vemos a realidade estão sempre relacionados com os modos como somos construídos, com nossas experiências, nossos sistemas de valores e crenças, nossas posições no mundo. Se nossa realidade é heterogênea, assim como o sujeito; se tanto o mundo quanto as pessoas mudam o tempo todo; se nossos mundos internos e externos são múltiplos e dinâmicos, então não pode haver um congelamento permanente do movimento, da mudança, do nosso encontro com outras subjetividades, nem da transformação que tal contato promove. Contanto que o contato seja dialógico no sentido bakhtiniano ${ }^{2}$, ou seja, um contato no qual as subjetividades envolvidas se abrem umas para as outras e se engajam na interrogação de si mesmas e uma da outra em decorrência de tal contato, então não pode haver outra forma de diálogo do que a negociação e o constante reposicionamento. Um contato no qual as partes se ocupam de tentar impor suas visões pré-construídas uma à outra só pode resultar em aniquilação e violência simbólica. Um diálogo no qual as partes se ocupam em questionar seus pressupostos mais caros tende a possibilitar a produção de novos pressupostos, e tais pressupostos poderão ser partilhados, mesmo que momentânea e contingencialmente.

Resumindo: somos todos seres subjetivos, interpretando ideologicamente o mundo dentro de nós e à nossa volta. A diferença entre um 
positivista, um relativista radical e um relativista pós-estruturalista está nos elementos discursivos ativados por cada um quando se encontram com a diferença. $\mathrm{O}$ positivista se ocupa de declarar sua perspectiva como formada de acordo com uma ordem "supernatural", com uma ética universal fundada em como as coisas "realmente são", o que o habilitaria a impor sua perspectiva a outros, já que ela estaria baseada num referencial totalitário e canônico. O relativista radical vai desengajar-se com a diferença, uma vez que tolerância e respeito à diferença implicam, para ele, a completa ausência de conflito no contato com o outro, uma ausência que é mais facilmente obtida pelo mero reconhecimento de que cada um tem o direito de permanecer como está: diferente, mesmo que "algumas diferenças sejam melhores do que outras". Já o relativista pós-estruturalista enfrentará seus encontros com a diferença como oportunidades para revisar sua posição, para engajar-se com seus pressupostos, para (re)instaurar suas práticas de construção de sentidos baseado na constatação de que modos diferentes de saber/conhecer não são certos ou errados em sua essência, mas são considerados certos ou errados conforme seus graus de correspondência com padrões éticos pessoais e com aqueles de suas comunidades interpretativas e contextos.

Sob tais princípios, o relativista pós-estruturalista vai necessariamente engajar-se com a diferença em vez de silenciá-la, pois a consciência da multiplicidade de perspectivas e identidades inibe a imposição de padrões ou modelos epistemológicos e culturais específicos; tal relativismo não restringe ou menospreza o engajamento em ações políticas afirmativas - ele simplesmente rejeita a pretensão de discursos que objetivam disciplinar consciências ou subjetividades, e busca aqueles que permitem o confronto, a tensão, o atrito e, portanto, a aprendizagem.

O quinto pressuposto importante, decorrente desse relativismo, é que a objetividade ou a razão lógica não são "os" caminhos que nos conectam a um mundo supostamente "real", mas são entendidas como manifestações do que Derrida (1993) chamou de "metafísica da presença", ou seja, o desejo de obter acesso imediato a uma realidade ou verdade essencializadas. "Presença" para Derrida é a invenção ou a ilusão de que existiria uma realidade fundamental, dada, independente do observador; essa noção de realidade é apresentada por Derrida como o alicerce de nossas teorias mais valorizadas e aceitas sobre verdade. A crítica de Derrida (1973) desconstrói a ciência, um discurso fundado nesse tipo de 
metafísica, ao demonstrar que nossos pensamentos, incluindo aí a razão científica, são interpretações produzidas em discurso e portanto só podem nos oferecer um acesso sempre mediado à realidade: a ciência constrói realidades discursivas utilizando procedimentos interpretativos construídos por ela mesma para entender o mundo, produzindo assim explicações calcadas numa cadeia de relações de différance dentro do campo da ciência, instaurado pela própria ciência. Em suma, não podemos separar a mente de sua existência no mundo social, não podemos desengajar nossos pensamentos e entendimentos das práticas discursivas que os constroem em nossas vidas concretas (como ilustra o desenho do holandês Escher, na Figura 3).

\section{Figura 3 - Subjetividade/objetividade}

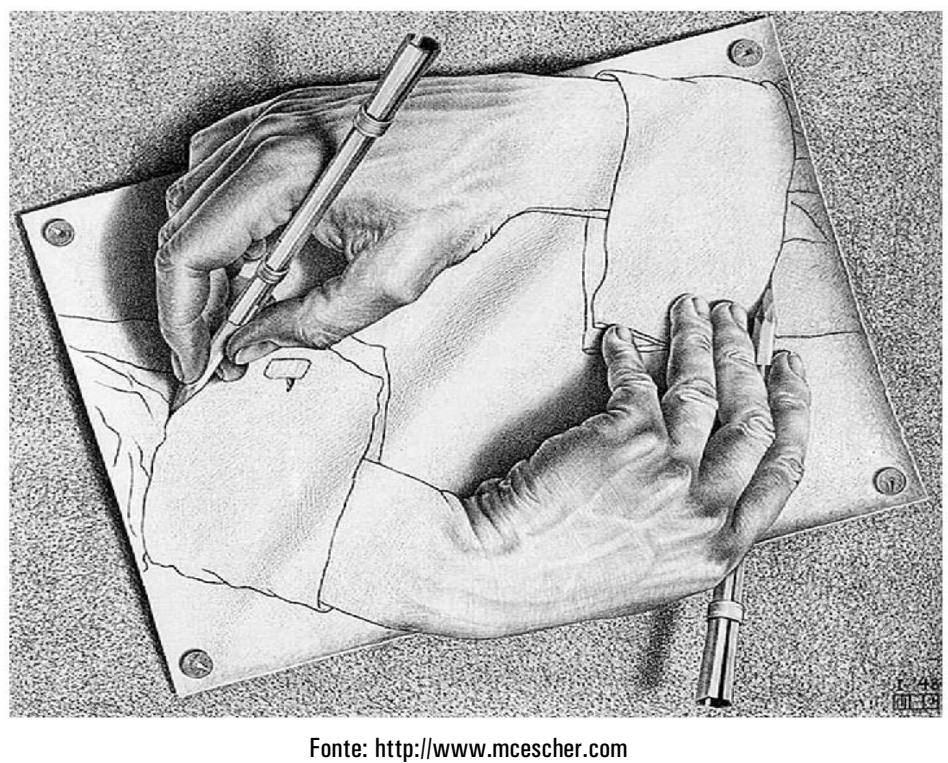

Além disso, esse discurso que nos constitui não é transparente, mas opaco: não há garantias de que a mensagem transmitida será recebida como pretendida pelo seu emissor, sem mencionar a dificuldade envolvida em descobrir qual a mensagem "realmente" transmitida. Inúmeros fatores, tanto interna quanto externamente à troca de formas estritamente linguísticas, influenciam a comunicação. Entre tais fatores é preciso considerar o posicionamento atribuído às pessoas envolvidas no 
processo, o lócus de produção, as múltiplas camadas contextuais constituídas em cada prática social, como as ideologias, as culturas, as perspectivas contextuais dos participantes fisicamente presentes ou ausentes, e assim por diante.

Se a linguagem é entendida como discurso, como tendo sua existência em meio a relações culturais, ideológicas, sociais e culturais, sendo, portanto, culturalmente determinada e constitutiva de nossos processos de construção de sentidos, então os discursos da ciência e da racionalidade devem ser vistos como produzidos eles também em meio a práticas sociais e assim vinculados a cultura, gênero, etnicidade, classe social, posicionalidade. Não há como distanciarmo-nos do discurso, e tentativas de estabelecer caminhos para a "salvação" por meio da neutralidade/objetividade acabam funcionando como tentativas de opressão política, tornando-se simbólica ou fisicamente violentas.

Saber é, desse modo, engajar-se em práticas de significação, construir sentidos de dentro de perspectivas específicas - quer sejam eles reconhecidos como válidos e eficientes, quer não. A ciência é, portanto, "um" domínio explicativo dentre outros. Mas vale aqui um alerta: negar à ciência uma natureza transcendente não é o mesmo que "abandonar a ciência": é, isto sim, posicioná-la em sua existência ideológica, interpretativa, narrativa, entendê-la como uma entre várias práticas sociais de construção de sentidos. A ciência não é uma prática inocente ou descorporificada, equivalente socialmente a qualquer outra: ela está imersa nas práticas e valores que ela própria ajuda a instituir (MATURANA, 2001). Tendo sua existência nas práticas sociais, os discursos científicos ocupam posições de grande prestígio em muitas sociedades contemporâneas, nas quais ser reconhecido/a como integrante de uma comunidade científica pode ser de interesse estratégico a muitos indivíduos e instituições. Os discursos da ciência vêm imbuídos de uma aura de verdade - muitas das sociedades que partilham os princípios discursivos ocidentais posicionam a ciência, na melhor das hipóteses, como o repositório dos discursos mais próximos da realidade e, na pior das hipóteses, como espaço onde se produz a verdade, capaz de revelar a essência, a natureza das coisas "como realmente são". Resulta disso que a ciência tem se desenvolvido como uma instituição em si mesma, como uma espécie de religião com suas próprias seitas, seguidores, iniciados, traidores, sacrifícios, punições e recompensas característicos do domínio científico. 
Programas de graduação e pós-graduação estão entre os exemplos mais familiares desse contato ritualístico com a ciência e o saber acadêmico na sociedade. Por meio dos cursos universitários, pessoas "comuns" se tornam cientistas depois de sobreviver a rituais de iniciação que, eventualmente, irão transformá-las em pessoas esclarecidas, em estudiosos cultos que sabem mais e melhor do que os não-iniciados, em especialistas que alcançaram uma posição elevada no conhecimento de sua(s) disciplina(s). Uma vez que seu valor e sua dedicação passam no teste de perseverança e fidelidade aos princípios acadêmicos, uma vez abalizados pelos já-iniciados professores universitários, nossos novos cientistas podem então ter a chance de formar outros cientistas como eles, tornando-se, por sua vez, professores também, repetindo o padrão incessantemente.

O conhecimento institucionalizado em cursos universitários pode, consequentemente, ser de grande importância para o desenvolvimento de identidades sociais positivas para grupos sociais marginalizados, especialmente no caso de imigrantes e seus descendentes. Desde que esses futuros cientistas sejam encorajados a problematizar suas posições antes, durante e depois dos rituais de iniciação, bem como questionar como tais posições são construídas na sociedade ou, em outras palavras, desde que os graduandos sejam estimulados a "desaprender" seus privilégios (SPIVAK, 1994), a inserção de grupos étnica e socialmente marginalizados e seus saberes locais na estrutura acadêmica das universidades pode ser um modo efetivo de construir um senso de pertencimento em tais grupos, bem como influenciar práticas legitimadas com seus modos talvez alternativos de conhecer. Esse é um dos objetivos do currículo das habilitações em japonês e polonês do curso de Letras que vem descrito e comentado a seguir.

\section{0 currículo de Japonês e Polonês}

Embora não seja de amplo conhecimento nem mesmo dos habitantes de Curitiba, a cidade tem uma grande comunidade polônica, tendo recebido 95\% dos 60 mil imigrantes poloneses que chegaram ao Brasil entre 1869 e 1920. O Brasil também tem a maior comunidade de imigrantes japoneses no mundo, e a segunda maior do país está no Paraná. 
Mesmo assim, os cursos de graduação em Letras na região não costumam incluir polonês ou japonês em suas habilitações. Esse silêncio pode ser atribuído à posição marginal ocupada por essas comunidades no cenário epistemológico global (embora a cada uma seja atribuído um grau diferente de marginalidade conforme a comunidade em que se inserem), mas também a questões locais envolvendo o ensino e a aprendizagem de línguas modernas.

Evidentemente, as várias línguas estrangeiras são posicionadas social e academicamente de modo diferente conforme sejam percebidas em termos de seu impacto social, político, econômico e epistemológico, mas não cabe, neste momento, aprofundar o lugar de cada uma. A referência a tal posicionamento se faz aqui em relação à distinção feita academicamente entre o trabalho com a língua materna e com as línguas estrangeiras em geral: cada um desses dois grupos ocupa lugar diferenciado nos cursos de Letras, e tais lugares posicionam os sujeitos que se ocupam de uma ou das outras como sendo sujeitos mais ou menos "relevantes" para o desenvolvimento da sociedade brasileira.

Fica fácil perceber, nos momentos em que a diferença "professor de língua materna" e "professor de língua estrangeira" é mobilizada, que o papel atribuído aos "técnicos de ensino de língua estrangeira" é menosprezado inclusive por aqueles que o recebem, considerado de menor importância e, portanto, menos "acadêmico", numa reprodução da oposição clássica "mente X corpo". A mente, responsável pelas funções cognitivas superiores, seria o lugar associado ao trabalho com a língua materna; ela seria o espaço "descorporificado" mais nobre da atividade científica, o lugar onde se produzem as teorias que eventualmente poderão vir a ser "aplicadas" para o benefício do corpo. Já o corpo, espaço da "prática" ligado às necessidades materiais dos seres humanos, estaria representando o trabalho com as línguas estrangeiras, voltado a necessidades cotidianas específicas, incapaz de produzir teorias porque centrado na resolução de problemas concretos que impediriam a visão de um todo generalizado.

Esse pensamento binário ajudou a construir uma distinção marcada entre teoria e prática e o consequente privilégio que se dá ao primeiro termo dos binários. Derrida caracterizou essa operação distintiva entre teoria e prática ou mente e corpo como central ao pensamento ocidental (1976; 1993) e, assim, determinante de uma série de acontecimentos epis- 
temológicos com desdobramentos importantes para como o mundo ocidental caracteriza o conhecimento e as diferentes formas de conhecer. Esse binarismo parece reverberar também na estrutura curricular das habilitações tradicionais do curso de Letras da UFPR, materializada no foco disciplinar do currículo e na estrutura $3+1$ da formação profissional prevista, que, mesmo após o ajuste curricular em função das DCEMEC de 2004, pedindo a quebra dessa estrutura, continuam a informar o currículo da graduação ${ }^{3}$.

Mesmo considerando esse cenário, a criação de um novo currículo não foi motivada apenas por um "ato de rebeldia" diante de tal estado de coisas. Foi motivada também, e talvez se possa dizer principalmente, pela vontade de construir uma alternativa à prática tradicional de ensino na nossa universidade: em vez de reproduzir os currículos usuais, baseados numa perspectiva transmissiva de conhecimento canônico, insistimos em lutar por uma oportunidade de criar espaços para que uma visão de educação como atividade complexa pudesse ter lugar, de modo que se pudesse construir um currículo no qual teoria e prática fossem trabalhadas num processo colaborativo entre alunos e professores.

O currículo foi então construído a partir da percepção de que simplesmente a construção de um espaço para duas habilitações novas entre várias outras não produziria os efeitos que esperávamos: sendo nós, professores de línguas e literaturas estrangeiras, os "outros" do discurso legitimado que privilegia a teoria em detrimento da prática, precisaríamos marcar essa diferença para construir legitimidade para as novas habilitações. Mas seria preciso também incluir-se de fato no curso vigente, integrando os professores, as disciplinas e os alunos das várias habilitações. A fim de legitimar a presença das habilitações de Japonês e Polonês, inserindo-as no grupo não como "excentricidades do pessoal das línguas estrangeiras", mas como designs de identidades e epistemologias valorizadas e aceitas pela comunidade acadêmica, precisávamos oferecer aos alunos e aos professores (alguns antigos, outros recém-contratados, estrangeiros e brasileiros, mas todos residentes no Brasil há mais de 15 anos) a chance de contarem e recontarem suas histórias, de confrontarem narrativas e assim reescreverem a si mesmos em sua interação com os outros.

Para que essa interação e inclusão acontecessem, era preciso que as narrativas de representação dos grupos fossem explicitadas, e não silenciadas, na perspectiva de que a alteridade deve ser reconhecida para que 
possa ser respeitada. Taddei (2000, p. 177) aponta quatro maneiras pelas quais a diferença é normalmente silenciada: (1) ao se considerar que narrativas alternativas sejam logicamente absurdas, impossíveis ou equivocadas; (2) ao se inserir tal raciocínio na relação com o outro, de modo que se ver rotulado como "diferente" seja uma ameaça que o silencie; (3) ao extirpar do outro sua alteridade, por meio de tecnologias específicas, como direitos legais, e/ou; (4) pela falta de reconhecimento da dor envolvida em ser diferente. Esses mecanismos discursivos operam como forças simbólicas que marcam a diferença como invisível e assim produzem uma "outredade" muda, porque ilegal e deslegitimada.

Nesse ano e meio de experiência das novas habilitações, foi possível perceber esses movimentos de silenciamento em diversas ocasiões, como nos momentos em que professores do curso não aceitavam a matrícula dos alunos dessas habilitações em suas disciplinas e foi preciso intervir; ou ainda quando aos alunos dessas habilitações era vetada a matrícula em disciplinas de outros turnos, mesmo sendo esta uma prática usual dos alunos de todas as outras habilitações; ou mesmo quando os alunos procuravam professores de outras habilitações no curso para conversas acadêmicas sobre seus interesses de pesquisa e ouviam comentários depreciativos sobre seus professores e sobre a estrutura curricular de suas habilitações.

Para Tadei (2000, p. 183), a inclusão e a exclusão contribuem enormemente ao processo de construção de identidades e, por isso, para entendermos o processo de inclusão, precisamos entender o funcionamento de seu contraponto, a exclusão, como forma determinante de nossas identidades. A exclusão é baseada no que Taddei chama de "necessidade histérica de auto-conhecimento, auto-afirmação, pela admissão da possibilidade da auto-negação", assim, a necessidade de excluir outros está diretamente ligada à sensação de que o self também pode ser excluído por outros e especialmente por seu próprio self. Nas palavras de Taddei (2000, p. 183):

Os excluídos são a materialização da negação do grupo, e ao mesmo tempo das condições de sua própria definição. $O$ grupo, os identificados como "nós", são assolados pela obsessão da pureza, isto é, da distinção entre a inclusão e a exclusão. Este "nós" está sempre a se testar, a reafirmar (ou não) a sua "pureza", a condição para a participação neste "nós", configurando uma situação de "terror": o terror da ridicularização, da queda na escala social (que 
deve ser escondida a todo custo), o terror do envelhecimento, de estar "parado no tempo", de ser identificado como portador de um "mau gosto" ou de "falta de educação".

Um dos problemas das questões sobre inclusão/exclusão está em como as pessoas tendem a aderir prontamente às representações feitas delas mesmas, por elas e por outros, tratando identidade como algo fixo e dado, em vez de fluido, dinâmico e construído. Narrativas e representações são assim coladas às pessoas como rótulos e precisam ser desconstruídas em sua natureza discursiva, a fim de que se possa lidar com a discriminação a partir de sua discursividade, e não de sua suposta essencialidade.

Currículos de graduação, nos quais profissionais estão sendo instruídos, formados, educados, podem ser um local privilegiado para tal desconstrução. A seguir, serão enfocadas algumas das principais características do novo currículo que o posicionam como alternativa aos currículos tradicionais, bem como será apresentada uma análise inicial da experiência com esse currículo em seu segundo ano de implementação.

\section{0 currículo}

Neste texto, currículo está sendo entendido a partir do domínio da linguagem, no contexto específico do ensino superior nas áreas de literatura e linguística nos cursos de Letras. Currículo aqui é visto como um documento educacional que marca um território político, refletindo, reforçando e possivelmente modificando culturas, um espaço ideológico de poder ou, resumindo isso tudo, um "documento de identidade" (SILVA, 1999). Currículo aqui não é, portanto, simplesmente uma lista de disciplinas ou cursos a serem lecionados, mas sim o sistema planejado para que os alunos e professores possam tomar decisões informadas sobre seu posicionamento na estrutura epistemológica social e política do ensino de línguas e literaturas.

O currículo do programa das habilitações em Polonês e Japonês da UFPR foi desenvolvido pelo Departamento de Letras Estrangeiras, em 2007 e 2008. Um de seus objetivos é oferecer à comunidade local a oportunidade de ver seus conhecimentos e culturas não apenas respeitados e representados, mas também academicamente legitimados. A legitimação 
dessas comunidades no curso de Letras acontece, em grande parte, num componente curricular específico chamado de Projetos de Aprendizagem, e é nesse elemento que se concentra a análise do currículo apresentada aqui. Esse é apenas um dos elementos curriculares, limitado a $1 / 5$ do número total de horas previstas para a formação dos alunos, sendo que os outros 4/5 do currículo giram em torno da estrutura disciplinar mais comum aos currículos de graduação em geral (ver anexo 1 para a estrutura curricular geral). Apesar disso, o componente Projetos de Aprendizagem caracteriza-se como um dos mais importantes do currículo, já que marca seu diferencial em relação às outras habilitações do curso de Letras da UFPR e exige o reposicionamento das funções de alunos e professores na formação universitária, tendo sido assim a figura mais polêmica das novas habilitações.

Os Projetos de Aprendizagem (doravante PA) são um componente modular distribuído uniformemente nos quatro anos do curso, em formato administrativo de disciplinas de 60 horas a cada semestre, com exceção do último ano do curso, em que os PA são substituídos pelo Trabalho de Conclusão de Curso (doravante TCC). Cada PA tem quatro aulas semanais, a maioria dedicada a estudos em grupo ou individuais, sem a presença ou vigilância de um professor. Essa já é uma grande inovação no currículo, pois as outras habilitações do curso têm grades horárias superlotadas com disciplinas. Uma vez que a maioria dos alunos, especialmente nos cursos noturnos (como é o caso das novas habilitações), trabalha durante o dia, uma das reclamações constantes dos alunos é que lhes falta tempo para estudar como gostariam - assim, os PA garantem um espaço para estudos individualizados e preveem que os alunos ocupem tempo da grade curricular para realizar atividades de estudo sem o controle de um professor. Com isso, começa-se a modificar o papel do aluno como um receptor passivo de conhecimento, atribuindo-se a ele um tempo "vago" que ele ocupará como achar mais produtivo. É um reconhecimento do que o aluno faz de qualquer maneira: mesmo estando fisicamente presente em sala de aula, o aluno acaba ocupando seu tempo como quer ou como pode, por vezes realizando outras tarefas, pensando em questões relacionadas a outras disciplinas ou acontecimentos, afastando-se mentalmente do que acontece em sala de aula para dar conta de questões alheias à disciplina ministrada pelo professor. Mas a ilusão de estar presente se mantém com a presença do corpo físico, mesmo estando 
ausente o corpo mental. E isso parece bastar em muitas situações de sala de aula.

A disciplina de PA é estruturada em torno de um eixo que se baseia na colaboração entre alunos e seus colegas e professores, bem como entre professores. O grupo todo envolve os alunos das duas habilitações e seus orientadores de PA; eles são responsáveis pelo andamento da disciplina, e decisões concernentes a questões gerais como avaliação e horários de encontros com todo o grupo são sempre negociadas no grande grupo. A estrutura de cada projeto específico, assim como os procedimentos para seu desenvolvimento e os critérios para sua avaliação são também discutidos no grande grupo - alunos e professores apresentam suas sugestões, que são debatidas no grupo em relação a cada projeto específico e negociadas coletivamente nos encontros gerais que acontecem normalmente uma vez por mês. Todos oferecem sugestões para todos e negociam o que pode ou não ser generalizado para o grande grupo. Desse modo espera-se construir uma sensação de responsabilidade partilhada sobre cada projeto, sob o pressuposto de que cada aluno tem o que dizer sobre cada um dos projetos, e que pode contribuir para o seu andamento durante o curso. Alunos e professores costumam envolver-se em mais de um projeto, contribuindo com sugestões nas reuniões do grande grupo ou mesmo participando dos encontros específicos para cada projeto.

Outra característica distintiva dos PA vem em seu próprio nome como projetos de "aprendizagem", e não de "pesquisa". Com isso querse lembrar que a "aprendizagem" pode acontecer em espaços outros que não exclusivamente os de pesquisa acadêmica, que aprendizagem nessas habilitações é vista como passível de ocorrer em diferentes atividades e de múltiplas maneiras na vida dos aprendizes, tanto dentro quanto fora da universidade. Os PA são, portanto, um convite para que alunos e professores exercitem sua criatividade, construindo espaços de aprendizagem que não se limitem às paredes das salas de aula.

Nos PA, os alunos podem escolher o tipo de projeto e de aprendizagem que querem construir na disciplina. Alguns exemplos dos projetos desenvolvidos pelos alunos do primeiro ano foram a preparação de exposições culturais sobre a cultura pop japonesa, a criação de um coro especializado em canções folclóricas polonesas, uma iniciação às artes marciais japonesas, um livreto sobre as celebrações de festas tradicionais 
nas comunidades polônicas da região de Curitiba. Para tanto, os alunos envolvidos tiveram de contatar outros departamentos e professores da universidade, bem como instituições culturais externas à universidade, apresentando-se e apresentando seus projetos em ambientes acadêmicos e não-acadêmicos, transitando por gêneros discursivos distintos e definindo seus interesses de estudo e como expressá-los em diferentes ambientes de prática social. Tais ações certamente envolvem trabalho de pesquisa, mas não precisam necessariamente transformar-se em pesquisa formal a fim de serem aceitos como formas legítimas de construir conhecimento no espaço dos PA.

Acima de tudo, essa disciplina trabalha na perspectiva do "conhecimento situado" (ESCOBAR, 2004), atendendo aos interesses individuais dos alunos, a seus conhecimentos prévios e a perspectivas profissionais específicas. O objetivo dos PA no currículo é construir uma visão de conhecimento como atividade localizada, incluindo conhecimentos locais na epistemologia legitimada pela universidade, atribuindo-lhes um espaço formal no currículo como um primeiro passo, para, em seguida, trabalhar com tais conhecimentos, trazendo e valorizando formas diferentes de saber junto às práticas de aprendizagem de alunos e professores. Tal atitude é inclusiva, no sentido de que se recusa a silenciar conhecimentos e modos de conhecer específicos, sejam eles locais ou globais, e as identidades que se relacionam a eles.

O fato de os PA não serem necessariamente orientados por professores com conhecimento da língua de habilitação dos alunos é outra característica do trabalho com os PA que tem causado bastante estranhamento tanto entre alunos quanto entre professores. Alguns alunos afirmaram que seus projetos só começariam "mesmo" a se desenvolver quando eles tivessem a oportunidade de ser orientados por professores da língua de sua habilitação. De fato, os projetos propostos se beneficiariam do contato direto com especialistas; entretanto, ter de buscar esse contato tem, ao mesmo tempo, representado um exercício importante no desenvolvimento, se não dos projetos em si, certamente dos alunos e de seus orientadores - estes precisam reconhecer que necessitam da ajuda de colegas professores de outras áreas para colaborar com os interesses de seus alunos, e que podem ampliar, desse modo, seu conhecimento, ao mesmo tempo em que ensinam outros conhecimentos; os alunos precisam construir maior independência e transitar por outros espaços na 
universidade e fora dela, percebendo que o conhecimento importante para seus campos de atividade não é uma prática restrita aos especialistas de seu curso, nem aos bancos universitários. Como resultado, tanto alunos quanto professores têm a oportunidade de vivenciar a arbitrariedade das divisões do saber em "áreas de conhecimento", bem como de problematizar a posição do professor universitário como fonte de conhecimento o que não tem sido bem-recebido por alguns - e questionar o pressuposto de que a universidade seria o local onde alunos encontrariam ícones de sapiência e por eles seriam iluminados. Evidentemente, tais preconceitos e expectativas ainda assombram mesmo os alunos que já passaram por um ano e meio de PA: o mito do conhecimento completo e acabado, encerrado num cérebro especialista, ainda paira fortemente sobre os alunos e professores.

Entretanto, o espaço para a ressignificação de tais mitos está criado. A participação nos PA convida ao desafio dos papéis fixos de aluno e professor na universidade, permitindo o questionamento das posições designadas aos sujeitos na epistemologia universitária e na estrutura da academia. Não é preciso dizer que convites ao confronto de perspectivas e possibilidades como essa não vêm sem conflito e, mesmo que timidamente, estabelecem uma necessidade constante de justificarmos nossas escolhas, o que nos leva a perceber alternativas possíveis.

Portanto, ao lidar com os alunos e suas perspectivas locais, ao tentar entender com eles as implicações da exclusão/inclusão epistemológica e ontológica de suas formas de saber e de estar no mundo, estamos também permitindo a eles construir e exercitar identificações que se ofereçam como alternativas à usual aceitação das narrativas construídas apesar deles mesmos, diante das quais muitas vezes se promove uma negação de si e uma assimilação das representações dominantes. Tal procedimento tem o potencial de reposicionar conhecimentos, formas de conhecer, identidades e identificações num espaço que permita a abertura para um questionar e um reescrever constantes. Esse potencial pode levar à construção de um lugar epistemológico em que se possa revelar "a ambivalência na origem dos discursos tradicionais sobre autoridade e possibilitar uma forma de subversão, fundada na incerteza que transforma as condições discursivas da dominação em espaços de intervenção" (BHABHA, 1985, p. 144.) 


\section{Os docentes}

Um desses espaços de intervenção em que os PA têm causado grande comoção é aquele do papel do professor universitário. Ao final do terceiro semestre, desde a existência dos PA no currículo, fizemos uma pesquisa junto aos professores para conhecer suas perspectivas sobre a experiência de orientar os alunos no desenvolvimento de seus projetos. Essa pesquisa utilizou questionários escritos com perguntas diretas sobre a avaliação que os professores faziam tanto da disciplina em si no currículo quanto de sua experiência como orientadores.

Ao serem perguntados sobre sua experiência, muitos pareceram sentir-se integrados à proposta curricular e responderam entusiasmados com a novidade, aparentemente convictos de estarem tendo uma oportunidade de rever seu papel como professores e exercitar outras possibilidades além da tradicional "transmissão de saber":

Tive uma agradável surpresa ao perceber que, depois de oito anos afastada do ambiente acadêmico - já havia lecionado durante seis anos em outra universidade, onde o exercício da docência não veio de encontro às minhas expectativas - passei a ter uma relação diferente com os alunos e com o meu trabalho.

Avalio minha experiência como muito interessante, uma vez que tive a oportunidade de aprender muito com as pesquisas realizadas pelos alunos.

Gostei muito porque foi a primeira vez que pude ver alunos de graduação discutindo sobre temas que gostariam de pesquisar, unirem-se em grupos por área de interesse, desenvolverem suas pesquisas sem necessariamente terem um professor orientador da área de polonês e japonês, e, finalmente, compartilharem seus progressos e resultados com os alunos de outro curso.

Apenas um professor, no entanto, admitiu abertamente estar decepcionado com o "baixo rendimento" dos alunos e desconfortável com o fato de ter sido colocado em posição de fragilidade e incapacidade para "efetivamente" contribuir com os alunos:

É uma experiência interessante, porém não me sinto bem tendo que orientar os assuntos que não domino. Creio que os alunos também preferem ser orientados pelas pessoas da área deles.

Educação em Revista | Belo Horizonte | v.27 | n.02 | p.249-276 | ago. 2011 
Outro, oferecendo um indício apenas de sua insatisfação, avaliou o processo como "assustador" e, por isso, difícil de compreender:

Imagino que o "excesso de liberdade" proporcionado pelos PA tem assustado tanto professores como alunos, o que dificulta o entendimento dos objetivos desses Projetos.

O confrontar-se com posições novas, com o papel de "orientar" sem dominar os conteúdos de que os alunos necessitam para desenvolver seus projetos, implica um reconhecimento de que a aprendizagem envolve mais do que o domínio de conteúdos estáticos ou fórmulas de saber, abrangendo também procedimentos investigativos, busca de caminhos e desenvolvimento de estratégias e recursos para estabelecer relações com diferentes formas de conhecimento. Mais do que informar transmitindo conteúdos, o professor de PA precisa preparar-se para orientar os alunos em sua busca por conhecimento de diversas formas, e não apenas com a leitura de textos acadêmicos sobre os assuntos relacionados aos temas dos PA.

Os alunos fazem incursões em diversos domínios do saber, transitando por várias formações discursivas e desenvolvendo procedimentos para lidar com os discursos de cada formação e seus entrecruzamentos o professor orientador poderá não conhecer tais domínios, mas mesmo assim continuará orientando seus alunos no desenvolvimento do projeto. Tal possibilidade assusta porque retira das mãos do professor o controle do processo, levando os alunos a assumirem boa parte da responsabilidade pelo andamento de seu aprendizado. Se o professor não está orientando os alunos por ser um especialista no campo escolhido para o projeto, mas sim porque tem mais experiência e ocupa uma posição diferenciada na estrutura universitária, então os alunos terão de compartilhar com ele seus saberes específicos e buscar colaborativamente caminhos para seu desenvolvimento acadêmico. Podemos arrematar essa discussão com as palavras de Sharon Todd (2009, p. 20), ao afirmar que

... o respeito, a dignidade e a liberdade que têm se tornado significantes de humanidade não são criados a partir do interior do indivíduo, mas na relação com o evento provocador e perturbador de ser confrontado por outra pes$\mathrm{soa}^{5}$. 
Tal confronto a que alunos e professores de PA são submetidos na estrutura curricular tem o potencial de construir nos sujeitos envolvidos uma atitude de "respeito, dignidade e liberdade" para consigo mesmos e para com os outros em seu percurso acadêmico. Contudo, ainda segundo Todd, a abertura para o diferente é um processo difícil e arriscado, uma vez que pressupõe uma espécie de "abandono" do self em detrimento da recepção integral do other.

Esse potencial de respeito, dignidade e liberdade que se pode vislumbrar na presença dos PA na estrutura curricular, entretanto, tem existência na prática acadêmica, em que se encontra atravessado por diferentes discursos e imerso em relações de poder. Os sujeitos dessa prática também se caracterizam por uma multiplicidade de determinações e discursos, entrecruzados todos na arena de conflitos que Bakhtin (Volochinov) definiu como língua (1999). Isso significa perceber que os desdobramentos de qualquer componente curricular se dão na prática contextualizada, localizada em tempo e espaço específicos e marcadas por sujeitos também específicos. Assim, corporificados em sua existência social, os PA se desenvolvem em meio a reações de acolhida e rejeição, de recusa e aceitação - e os sujeitos envolvidos neles agem e reagem à sua prática acadêmica conforme os projetos tomam corpo.

\section{Considerações finais}

A construção de identidades híbridas que se formam num processo de desenvolvimento de atitudes de abertura à diferença e reconhecem a instabilidade e dinamicidade das narrativas sociais parece permitir que os sujeitos assim caracterizados se beneficiem mais do mundo contemporâneo, também considerado um "multiverso" (MATURANA, 1999). Tais identidades recusam referências metafísicas universais, contextualizando práticas sociais (incluindo aquelas de interpretação e construção de conhecimentos) e estabelecendo diálogo no sentido bakhtiniano, como uma confrontação de perspectivas. Não há neutralidade possível quando se lê o mundo: pensamos sempre a partir de posições específicas que constroem nossas perspectivas e entendimentos em qualquer domínio, da ciência ao conhecimento cotidiano.

Os discursos da ciência que tentam criar e manter um conhecimento de elite, baseado no pressuposto de que algumas formas de co- 
nhecer seriam intrinsecamente superiores, e assim também o seriam os sujeitos que delas compartilham, são formas de pensamento que produzem determinados modelos de ensino/aprendizagem baseados na superioridade de certas formas de conhecer diante de outras, na maior qualidade de alguns saberes do que de outros, e, desse modo, posicionam como superiores também os sujeitos que dominam alguns saberes em detrimento dos sujeitos que dominam outros saberes. Se tais modelos, por um lado, se apresentam esvaziados de sentido para aqueles que não compartilham desse pressuposto, por outro lado, se tornam especialmente prejudiciais para quem, mesmo se percebendo excluído da epistemologia desejada (exclusão que pode se dar por várias razões, sejam elas de ordem econômica, política, social ou cultural), adota tal procedimento interpretativo de leitura do mundo. Eles prejudicam especialmente esses sujeitos na medida em que os colocam na posição de desejar algo que os rejeita, que os torna invisíveis e assim os anula enquanto agentes em meio às práticas discursivas que os constituem.

Portanto, práticas de ensino/aprendizagem que contextualizem a discursividade do conhecimento acadêmico e legitimem outros saberes e outras formas de conhecer são importantíssimas, especialmente no século XXI, período a que nos referimos como a "era do conhecimento" (GILBERT, 2005). Diferentes organizações curriculares, quem sabe em torno de "objetos de conhecimento" em vez de "disciplinas", ou seja, envolvendo projetos e problemas em vez de girarem em torno de disciplinas acadêmicas a serem dominadas pelos alunos, poderão trazer para dentro das universidades um movimento em direção ao que Santos (2008, p. xxxix) almeja ao defender a construção de novas formas de conhecimento, ou seja, "o reconhecimento de sistemas plurais de conhecimentos, alternativos à ciência moderna ou em articulação com ela e criando novas configurações de conhecimentos"

Os PA nas habilitações de Japonês e Polonês no currículo do curso de graduação em Letras da UFPR têm a configuração necessária para que alunos e professores ressignifiquem suas práticas identitárias e se reposicionem diante de si mesmos, uns dos outros e de diferentes esferas do conhecimento, reconhecendo a natureza híbrida e dinâmica de suas identificações e posições. Entretanto, não é sem crises e confrontos que o espaço se abre para esse reconhecimento: deslocarmo-nos de nossas zonas de conforto para zonas de confronto envolve muito mais do que uma inversão de letras 
nas palavras - exige arriscar-se na abertura para o outro (TODD, 2003), sobreviver na instabilidade das práticas sociais, agir sobre elas e compartilhar com outros o que aprendemos nas palavras vividas na prática social.

Afinal, como afirma Todd (2003, p. 85), o risco (“fine risk") faz parte do agir com responsabilidade em relação ao outro e, portanto, vale a pena considerarmos o papel de nossas instituições educacionais quando tentam estabelecer um ambiente "protegido" da prática social. Nas palavras de Todd (2003, p. 20):

Há algo profundamente arriscado em vir a saber, envolvendo renúncia e sacrifícios por vezes grandes demais para suportar. Os alunos frequentemente sentem que, uma vez vencida a batalha para aprender alguma coisa, eles não poderão mais ser os mesmos. E se essa batalha não bastasse, o processo retorna incessantemente, recusando-se a permitir conforto por muito tempo. Os egos não são formados, nem os desejos aplacados definitivamente. O ego nunca está acabado, mas é sempre incompleto, não é um "estado que se atinge, mas sim.... uma situação ativa". Isso significa que o ego é continuamente vulnerável à potencialidade da violência, à recorrência do aprender a tornar-se ${ }^{7}$.

Essa vulnerabilidade em que nos coloca o "aprender a tornar-se" não pode ser excluída da universidade, silenciada na construção de um mundo à parte das práticas sociais para as quais a universidade explicitamente afirma preparar os graduandos. Há sempre um ou vários riscos envolvidos em se confrontar uma narrativa, uma disciplina, um saber; há risco em relacionar-se simbolicamente com formas de conhecimento, com currículos, com o outro; a relação com o outro representa risco - risco de mudar perspectivas, conceitos, pressupostos e maneiras de pensar. Ao colocarmo-nos frente a outras histórias estamos correndo o risco de construir não apenas uma "provocação semiótica", mas uma "crise ontológica" (TODD, 2003, p. 18). O que parece estar em risco aqui é a identidade mesma do aprendiz, suas possibilidades de posicionamento, sua localização nas estruturas sociais. E esse "fine risk" vale a pena ser vivido, pois sem ele não acontece o aprendizado nem a relação responsável para com o outro. Novas figuras curriculares, o contato com novas formas de saber e novos conhecimentos trazem riscos; mas trazem com esses riscos possibilidades de aprender além das fórmulas mnemônicas e informações factuais - possibilidades de aprender responsiva e responsavelmente nas quais o investimento de nossas identidades pode ser recompensador. 


\section{REFERÊNCIAS}

BAKHTIN, M. (V. N. Volochínov). Marxismo e Filosofia da Linguagem. São Paulo: Hucitec, 1999.

BHABHA, H. K. Signs taken for wonders: Questions of ambivalence and authority under a tree outside Delhi, May 1817. Critical Inquiry, Local de publicação, v. 12, n. 1, 1985.

CASTELLS, M. O poder da identidade. Lisboa: Calouste Gulbekian, 2003.

CHOMSKY, N. New horizons in the study of language and mind. Cambridge: C.U.P, 2000.

DERRIDA, J. Structure, sign and play in the discourse of the human sciences. In: NATOLI, J.; HUTCHEON, L. A postmodern reader. Albany: State University of New York Press, 1993.

DERRIDA, J. Of grammatology. Baltimore: Johns Hopkins University Press, 1976.

ESCOBAR, A. "Worlds and Knowledges Otherwise": The Latin American modernity/coloniality Research Program. Cuadernos del CEDLA (Amsterdam), v. 16, p. 31 67, 2004.

FARACO, C. A. Interação e Linguagem: balanço e perspectivas. Conferência de encerramento do CONGRESSO INTERNACIONAL DE LINGUAGEM E INTERAÇÃO. São Leopoldo: UNISINOS, 2005.

FARACO, C.A. As idéias linguísticas do Círculo de Bakbtin. São Paulo: Parábola, 2009.

FREIRE, P.; MACEDO, D. Literacy: reading the word and the world. New York: Routledge, 1987.

FOUCAULT, M. Vigiar e punir: nascimento da prisão. Petrópolis: Vozes, 2002.

JORDÃO, C.M. Discurso e Identidade em Língua Estrangeira: Crusoé e Sexta-feira na Sociedade em Rede. In: RIBEIRO DOS SANTOS; ANDRELINO (Orgs.) Linguagens em Interação II: leitura e ensino de línguas. Maringá: Clichetec, 2010.

GILBERT, J. Catching the Knowledge Wave? The knowledge society and the future of education. Wellington: NZCER Press, 2005.

HALL, S. A identidade cultural na pós-modernidade. Rio de Janeiro: DP\&A, 2005.

HALL, S. Da diáspora: Identidades e mediações culturais. Belo Horizonte: Editora UFMG, 2006.

MATURANA, H.R.; VARELA, F. J. A Árvore do Conhecimento. Shambhala: Boston, 1992. MATURANA, H. R. Ciência, cognição e vida cotidiana. Belo Horizonte: Editora UFMG, 2001.

PIMENTA, S. G.; ANASTASIOU, L. G. C. Docência no ensino superior. São Paulo: Cortez, 2002. p. $144-153$.

SANTOS, B. de S. Another Knowledge is Possible: beyond Northern epistemologies. London: Verso, 2008. V. 3.

SPIVAK, G. C. Outside in the Teaching Machine. New York: Routledge, 1994.

TELES, G.M. Vanguarda Européia e Modernismo Brasileiro. Rio de Janeiro: Vozes, 1976.

TADDEI, R. R. Conhecimento, Discurso e Educação: contribuições para a análise da educação sem a metafísica do racionalismo. 196p. Dissertação (Mestrado em Educação) Faculdade de Educação, Universidade de São Paulo, Local de publicação (cidade), 2000. TODD, S. Learning from the Other. Levinas, psychoanalysis, and ethical possibilities in education. New York: Suny Press, 2003.

Educação em Revista | Belo Horizonte | v.27 | n.02 | p.249-276 | ago. 2011 
ANEXO 1 - Número de horas por componente curricular

\begin{tabular}{cc|cc}
\multicolumn{2}{c|}{ LICENCIATURA: 2.840h } & \multicolumn{2}{c}{ BACHARELADO: 2.360h } \\
\hline Formação Geral: & $300 \mathrm{~h}$ & Formação Geral: & $300 \mathrm{~h}$ \\
\hline Projetos de Aprendizagem: & $360 \mathrm{~h}$ & Projetos de Aprendizagem: & $360 \mathrm{~h}$ \\
\hline Trabalho de Conclusão de Curso: & $120 \mathrm{~h}$ & Trabalho de Conclusão de Curso: & $120 \mathrm{~h}$ \\
\hline Formação Específica: & $780 \mathrm{~h}$ & Formação Específica: & $780 \mathrm{~h}$ \\
\hline Optativas: (360 complementar) & $540 \mathrm{~h}$ & Optativas: (360 complementar) & $600 \mathrm{~h}$ \\
\hline Atividades Formativas: & $200 \mathrm{~h}$ & Atividades Formativas: & $200 \mathrm{~h}$ \\
\hline LIBRAS: & $60 \mathrm{~h}$ & & \\
\hline Formação de Professores: & $480 \mathrm{~h}$ & &
\end{tabular}

\section{NOTAS}

${ }^{1}$ Refiro-me à formação continuada que acontece de modo tênue em meio ao exercício da prática profissional, muitas vezes se dando de modo indireto e pouco perceptível, em contraposição ao que poderia ser uma formação continuada "oficial", fruto de ações explicitamente caracterizadas como tendo tal objetivo.

2 Segundo Faraco, "o diálogo no sentido amplo do termo deve ser entendido como um vasto espaco de luta entre as vozes sociais (uma espécie de guerra dos discursos), no qual atuam forças centrípetas (aquelas que buscam impor certa centralização verboaxiológica or sobre o plurilinguismo real) e forças centrifugas (aquelas que corroem continuamente as tendências centralizadoras, por meio de vários processos dialógicos....)" (2009, p. 69-70).

3 Mais informações sobre a atual estrutura curricular encontram-se no site do curso, em http://www.letras.ufpr.br

${ }^{4}$ No original: "the ambivalence at the source of traditional discourses on authority and enable[s] a form of subversion, founded on that uncertainty that turns the discursive conditions of dominance into the grounds of intervention".

5 No original: "the respect, dignity, and freedom which have become signifiers of humanity are not bred from within, but from the relation to the disturbing and provocative event of being confronted by another person".

$\mathbf{6}^{\mathbf{6}}$ No original: "the recognition of plural systems of knowledges, alternative to modern science or entering into articulations with the latter and creating new configurations of knowledges".

7 No original: "There is something profoundly at risk in coming to know, involving renunciation and sacrifices that are sometimes too great to bear. Students often feel that once they struggle to know something, they can never be quite the same again. And as if this struggle were not enough, the process continually returns, refusing to offer consolation for very long. Egos are not formed, nor are desires done away with once and for all. The ego is never finished but always incomplete, not "an attained state but... an active situation". This means that the ego is continually vulnerable to the potentiality of violence, to the recurrence of learning to become". 
Recebido: $19 / 07 / 2010$

Aprovado: 20/04/2011

Contato:

Universidade Federal do Paraná

Setor de Ciências Humanas Letras e Artes Departamento de Letras Estrangeiras Modernas

Rua General Carneiro, 460 - $9^{\circ}$ andar

Centro

CEP 80060-150

Curitiba, PR

Brasil

Educação em Revista | Belo Horizonte | v.27 | n.02 | p.249-276 | ago. 2011 